\title{
Adsorption of Chemically Prepared Cocoa Nibs Based Activated Carbon Onto Methylene Blue: Equilibrium and Kinetic Studies
}

\begin{abstract}
KhairulAdli Nikman ${ }^{1,2}$, Fisal Ahmad ${ }^{3}$, MohdSukri Hassan ${ }^{1}$, Khairunisa Nikman ${ }^{4}$ and Mohd Azmier Ahmad ${ }^{5,6 \star}$
${ }^{\prime}$ Faculty of Science and Technology, Universiti Sains Islam Malaysia, 71800 Nilai, Negeri Sembilan, Malaysia

2Jabatan Perubatan Forensik, Hospital Kuala Lumpur, 50586 Kuala Lumpur, Malaysia

${ }^{3}$ Cocoa Innovative and Technology Centre, Malaysian Cocoa Board, Lot 12621, 71800 Nilai, Negeri Sembilan, Malaysia

${ }^{4}$ Academy of Language Studies, Universiti Teknologi MARA Pahang, Bandar Tun Abdul Razak, Jengka, Pahang, Malaysia

${ }^{5}$ School of Chemical Engineering, Engineering Campus, Universiti Sains Malaysia, 14300 NibongTebal, Penang, Malaysia

${ }^{6}$ Solid Waste Management Cluster, Science \& Engineering Research Centre, Engineering Campus, Universiti Sains Malaysia, Nibong Tebal, Penang, Malaysia
\end{abstract}

\section{Article Info}

*Corresponding author:
Mohd Azmier Ahmad
Associate Professor
School of Chemical Engineering
Engineering Campus
Universiti Sains Malaysia
14300 Nibong Tebal, Penang, Malaysia
Tel: +604 5996459
Fax: +604 5996908
E-mail: chazmier@usm.my

Received: March 23, 2017

Accepted: April 4, 2017

Published: April 10, 2017

Citation: Nikman KA, Ahmad F, Hassan MS, Nikman K, Ahmad MA. Adsorption of Chemically Prepared Cocoa Nibs Based Activated Carbon Onto Methylene Blue: Equilibrium and Kinetic Studies. Int J Petrochem Res. 2017; 1(1): 15-18.

doi: 10.18689/ijpr-1000104

Copyright: (c) 2017 The Author(s). This work is licensed under a Creative Commons Attribution 4.0 International License, which permits unrestricted use, distribution, and reproduction in any medium, provided the original work is properly cited.

Published by Madridge Publishers

\begin{abstract}
This study was aimed to prepare cocoa nibs based activated carbon (CNAC) via chemical activation for methylene blue (MB) dye adsorption from aqueous solution. The activation process was performed at $500^{\circ} \mathrm{C}$ under inert condition using $\mathrm{K}_{2} \mathrm{CO}_{3}$ as activation agent. The effect of contact time and initial concentration of adsorbate on the adsorption process were examined. Langmuir isotherm model fitted well the adsorption equilibrium data with monolayer adsorption capacity of $64.98 \mathrm{mg} / \mathrm{g}$ at $30^{\circ} \mathrm{C}$. The adsorption kinetic was found to follow the pseudo-second-order kinetic model.
\end{abstract}

Keywords: Activated carbon, Chemical activation, Cocoa nibs, Methylene blue.

\section{Introduction}

Water pollution has become a highlighted issue as some of the industrial effluent is directly discharged into the river and water bodies without proper treatment [1]. Dyes effluent treatments from textile industries are divided into biological, physical and chemical treatment processes. All these processes have different color removal capabilities, capital costs and operating rates [2]. Physical treatment via adsorption process using Agrowaste based activated carbon as adsorbent is among the most efficient and cheap method for dyes removal. Several studies on agrowastes have been employed to remove the contaminants such as methylene blue (MB) dye from the water bodies [3] [4]. Agrowaste is appreciated as economical, sustainable and ecologically friendly materials. In this study, an attempt was made to utilize cocoa nibs waste into activated carbon using chemical activation process. The performance of CNAC was studied in removing MB dye from aqueous solution.

\section{Experimental}

\section{Chemicals}

All reagents and chemicals used in the research were analytical grade chemicals. For impregnation process, potassium carbonate $\left(\mathrm{K}_{2} \mathrm{CO}_{3}\right)$ was used. Commercial methylene blue $\left(\mathrm{C}_{16} \mathrm{H}_{18} \mathrm{CIN} \mathrm{N}_{3} \mathrm{~S} \cdot 3 \mathrm{H}_{2} \mathrm{O}\right)(\mathrm{MB})$ textile dye was obtained from Sigma-Aldrich (M) Sdn Bhd. 


\section{Preparation of Stock and Test Solutions}

Stock solution of MB with concentration of $500 \mathrm{mg} / \mathrm{L}$ was prepared by dissolving approximately $0.50 \mathrm{~g}$ of $\mathrm{MB}$ in $1000 \mathrm{~mL}$ distilled water. Test solution of $M B$ ranging from $10 \mathrm{mg} / \mathrm{L}$ to $100 \mathrm{mg} / \mathrm{L}$ were prepared by subsequent dilution from stock solution.

\section{Production of Pellet}

The cocoa nibs waste was ground and sifted to a uniform size of $0.5 \mathrm{~mm}$ or smaller. The samples were shaped into pellets by compressing the mixture with a hydraulic press, in which the cocoa nibs were compacted into pellets with a specific density of $1.8 \mathrm{~g} / \mathrm{cm}$.

\section{Preparation of Activated Carbon}

The carbonization was performed by placing approximately $60 \mathrm{~g}$ of cocoa nibs pellet in a vertical furnace, which contained in a tubular stainless steel reactor. This step was carried outat $700^{\circ} \mathrm{C}$ for 1 hour under purified nitrogen (99.99\%) with flowrate of $120 \mathrm{~mL} / \mathrm{min}$. Then, the furnace was allowed to cold to ambient temperature. Char yield was determined using following equation:

$\%$ Yield $=\frac{w_{c}}{w_{i}} \times 100 \%$

where is the mass of char after carbonization process and $\mathrm{w}_{\mathrm{i}}$ is the initial mass of cocoa nibs pellet. An amount of dried char was added with $\mathrm{K}_{2} \mathrm{CO}_{3}$ at various impregnation ratio (IR) in a $250 \mathrm{ml}$ beaker. Both were mixed with deionized water to dissolve the salt. The IR was calculated as follows:

Impregnation ratio, $\mathrm{IR}=\frac{\mathrm{W}_{\mathrm{K}_{2} \mathrm{CO}_{3}}}{\mathrm{~W}_{\text {char }}}$

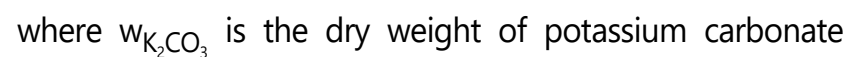
pellets and $w_{\text {char }}$ is the dry weight of cocoa nibs char. The mixture was then dehydrated in an oven at $105^{\circ} \mathrm{C}$ for 24 hours. The activation step was done using similar reactor as in carbonization step but at final temperature of $500^{\circ} \mathrm{C}$ under nitrogen flowrate of $120 \mathrm{~mL} / \mathrm{min}$ for 2 hours. The sample was then cooled to room temperature and washed with hot deionized water until the $\mathrm{pH}$ of the washed solution reached 6.5-7.

\section{Removal of MB by Batch Adsorption Study}

The batch equilibrium experiments of the adsorption capacity studies were conducted at $30{ }^{\circ} \mathrm{C}$ in a $250 \mathrm{~mL}$ conical flask in a water bath shaker. The stock solution $(1000 \mathrm{mg} / \mathrm{L})$ of $\mathrm{MB}$ was prepared by dissolving approximately weighed $1.0 \mathrm{gram}$ of the $\mathrm{MB}$ in $1000 \mathrm{~mL}$ of distilled water in a $1500 \mathrm{~mL}$ volumetric flask. The stock solutions were stored in dark place to prevent direct sunlight. The sample solutions were withdrawn at equilibrium to determine the residual concentration. The concentrations of the filtrates were measured using UV-Visible Spectrophotometer (Model Agilent Cary 60, USA).

\section{Effect of Initial Concentration}

In order to study the effects of initial adsorbate concentration, $100 \mathrm{~mL}$ of adsorbate solutions with known initial concentration $(10,25,50,80,100 \mathrm{mg} / \mathrm{L}$ of MB) were prepared in a series of $250 \mathrm{~mL}$ Erlenmeyer flasks. The amount of adsorbent that was added into each flask was fixed at $0.1 \mathrm{~g}$. The flasks were placed in an isothermal water bath shaker at temperature and rotation speed of $30^{\circ} \mathrm{C}$ and $120 \mathrm{rpm}$, respectively until equilibrium point was reached.

\section{Effect of Contact Time}

In order to study the effects of contact time on the adsorption uptake, $100 \mathrm{~mL}$ of adsorbate solutions with known initial concentration (10-100 $\mathrm{mg} / \mathrm{L}$ ) were prepared in a series of $250 \mathrm{~mL}$ Erlenmeyer flasks. The amount of CNAC that was added into each flask containing MB solution was fixed at 0.1 $\mathrm{g}$. The flasks were then placed in an isothermal water bath shaker of $30{ }^{\circ} \mathrm{C}$ with rotation speed of $120 \mathrm{rpm}$ for 360 minutes. The percent removal of adsorbate was calculated as follows:

$\%$ Removal $=\frac{\left(C_{i}-C_{e}\right)}{C_{i}} \times 100 \%$

Where $C_{e}$ is the concentration of adsorbate at equilibrium and $C_{i}$ is the initial concentration of adsorbate. The MB uptake at equilibrium is calculated as follows:

$$
q_{e}=\frac{\left(C_{i}-C_{e}\right) V}{m}
$$

where $m$ is the mass of the adsorbent and $V$ is the volume of the adsorbate.

\section{Adsorption Isotherm}

Adsorption isotherm study was carried out by fitting the equilibrium data to three isotherm model which are the Langmuir and Freundlich isotherm models, respectively represented by Equations (5),(6) and (7). The applicability and suitability of the isotherm equation to the equilibrium data was compared by judging the values of the correlation coefficients, $R^{2}$. The Langmuir model is atypical model used to measure the amount of adsorbate on an adsorbent at equilibrium. The relation is expressed by following equation [5]:

$$
\frac{1}{q_{e}}=\frac{1}{q_{m} K_{L} C_{e}}+\frac{1}{q_{m}}
$$

where, $q_{e}$ is the amount adsorbed $(\mathrm{mg} / \mathrm{g}), \mathrm{C}_{\mathrm{e}}$ is the equilibrium concentration of the metal ion $(\mathrm{mg} / \mathrm{L}), \mathrm{q}_{\mathrm{m}}$ is the maximum amount of adsorbed metal ion per unit mass of sorbent corresponding to complete coverage of the adsorptive sites $(\mathrm{mg} / \mathrm{g}), \mathrm{K}_{\mathrm{L}}$ is the Langmuir constant related to the energy of adsorption $(\mathrm{L} / \mathrm{mg})$

The Freundlich adsorption isotherm or Freundlich equations are a relation between the concentrations of a solute on the surface of an adsorbent, to the concentration of the solute in the liquid with which it is in contact. The relationship is stated as follows [6]:

$$
\begin{aligned}
& q_{e}=k_{f} c_{e}^{\frac{1}{n}} \\
& \log q_{e}=\log k_{f}+\frac{1}{n} \log c_{e}
\end{aligned}
$$

In this equation, $\mathrm{q}_{\mathrm{e}}(\mathrm{mg} / \mathrm{g})$ is amount of adsorbed material in adsorbent surface $k$ in arrangement are adsorption capacity and adsorption intensification. 


\section{Kinetic Model}

The kinetics of adsorption describes the rate of adsorbate uptake on activated carbon prepared and it controls the equilibrium time. The kinetics of adsorbate uptake is required for selecting optimum operating conditions for the full-scale batch process. Therefore, models for liquid-phase adsorption such as pseudo-first-order and pseudo-second-order were used to analyze the adsorption kinetic data. The pseudo-first-order kinetic model equation of Largergren [7] is generally expressed as:

$\ln \left(\mathrm{q}_{\mathrm{e}}-\mathrm{q}_{\mathrm{t}}\right)=\ln \mathrm{q}_{\mathrm{e}}-\mathrm{k}_{1} \mathrm{t}$

Where $q_{e}$ is the amount of adsorbate adsorbed at equilibrium (mg/g), $q_{t}$ is the amount of solute adsorb per unit weight of adsorbent at time $(\mathrm{mg} / \mathrm{g}), \mathrm{k}_{1}$ is the rate constant of pseudo-first order sorption ( $1 / \mathrm{h})$. The pseudo-second-order equation is expressed as [8]:

$\frac{\mathrm{t}}{\mathrm{q}_{\mathrm{t}}}=\frac{\mathrm{t}}{\mathrm{k}_{2} \mathrm{q}_{\mathrm{e}}^{2}}+\frac{\mathrm{t}}{\mathrm{q}_{\mathrm{e}}} \mathrm{t}$

Where $k_{2}$ is the rate constant of pseudo-second-order sorption (g/h.mg).

\section{Results and Discussion}

\section{Effect of contact time and MB initial concentration on adsorption equilibrium}

Figure 2 and Table 1 show the effect of various initial concentrations on adsorption of MB by CNAC. An equilibrium time of 100 min was needed for MB dye solution with initial concentrations of $10-25 \mathrm{mg} / \mathrm{l}$ to reach equilibrium. However, for initial concentrations of 50-100 mg/l, longer equilibrium times of 22-24 hours were required for the system to reach equilibrium. Initially, adsorbate molecules have to first encounter the boundary layer effect. Then it has to diffuse from boundary layer film onto adsorbent surface and finally, it has to diffuse into the porous structure of the adsorbent [10]. The ratio of the initial number of dye molecules to the available surface area was low at lower initial concentration compared to higher initial concentration. Therefore, MB solution with higher initial concentration would take relatively longer contact time to attain equilibrium due to the higher amount of MB molecules.

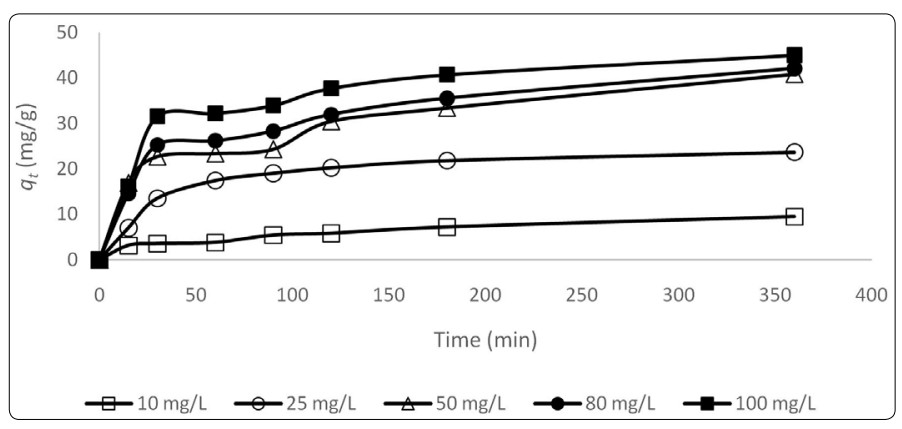

Fig. 2: Effects of contact time of MB onto CNAC
Table 1. MB percent removal by CNAC with IR 3:1

\begin{tabular}{ccccc}
\hline $\begin{array}{c}\text { Initial } \\
\begin{array}{c}\text { Concentration } \\
(\mathrm{mg} / \mathrm{L})\end{array}\end{array}$ & $\begin{array}{c}\text { Concentration } \\
\text { Left } \\
(\mathrm{mg} / \mathrm{L})\end{array}$ & $\begin{array}{c}\text { Concentration } \\
\text { Adsorbed } \\
(\mathrm{mg} / \mathrm{L})\end{array}$ & $\begin{array}{c}\text { Percent } \\
\text { Removal }(\%)\end{array}$ & $\begin{array}{c}\text { Concentration } \\
\text { adsorbed at } \\
\text { equilibrium, } \mathrm{q}_{\mathrm{e}} \\
(\mathrm{mg} / \mathrm{g})\end{array}$ \\
\hline 10 & 0.00 & 10.00 & 100.0 & 5.00 \\
25 & 5.04 & 19.96 & 79.8 & 9.98 \\
50 & 11.57 & 38.43 & 76.9 & 19.22 \\
80 & 25.16 & 54.84 & 68.6 & 27.42 \\
100 & 33.39 & 66.61 & 66.6 & 33.31 \\
\hline
\end{tabular}

\section{Effect of IR on adsorption equilibrium}

Fig. 1 shows the influence of IR on CNAC in removing MB. Sample impregnated with 2:1 ratio has the lowest capability to adsorb the adsorbate where the value is $27.8 \mathrm{mg} / \mathrm{g}$.

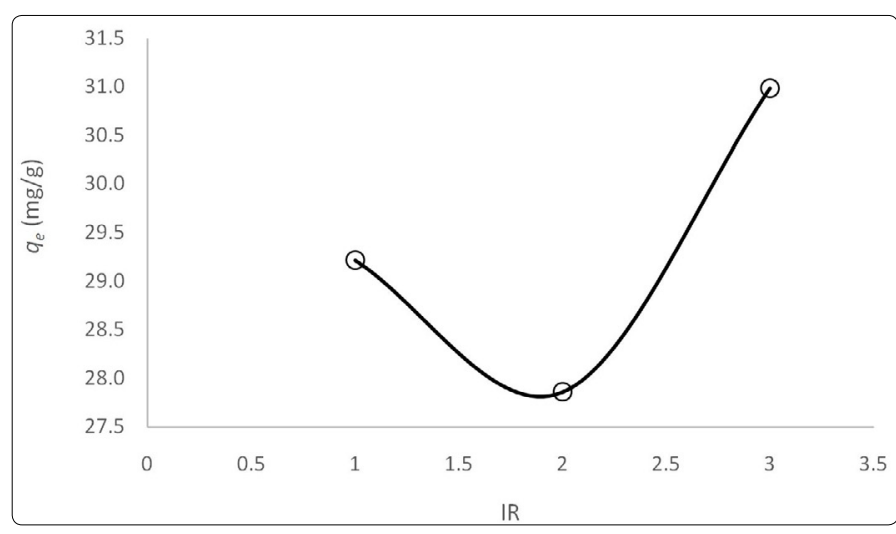

Fig. 1. Effect of IR on MB uptake

The adsorption capacity of CNAC was decreased with increased in IR from 1:1 to 2:1 before increased at IR of 3:1. CNAC with $3: 1$ ratio managed to adsorb $30.9 \mathrm{mg} / \mathrm{g}$ of $\mathrm{MB}$ at equilibrium. Higher IR was favorable for enhancing the $M B$ adsorption as more pores are developed on the sample surface [9].

\section{Adsorption Isotherm}

The most appropriate correlation for the equilibrium curve needs to be established in order to understand the adsorption system. Therefore, the equilibrium adsorption data were analyzed using the Langmuir and Freundlich isotherms as shown in Figure 3 whereas Table 2 summarizes all the constants from both isoterm models.

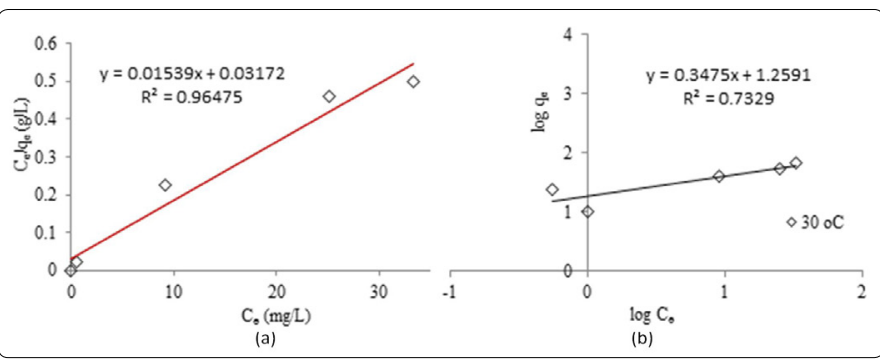

Fig. 3: Linear plots of (a) Langmuir and (b) Freundlich adsorption models

Table 2. Parameters of Langmuir and Freundlich adsorption isotherm for $M B$.

\begin{tabular}{ccccccc}
\hline & Equation & $\mathrm{R}^{2}$ & $\mathrm{q}_{\mathrm{m}}$ & $\mathrm{K}_{\mathrm{L}}$ & $\mathrm{K}_{\mathrm{f}}$ & $\mathrm{n}$ \\
\hline Langmuir & $\mathrm{y}=0.0154 \mathrm{x}+0.0317$ & 0.965 & $64.98 \mathrm{mg} / \mathrm{g}$ & 0.152 & $/$ & $/$ \\
Freundlich & $\mathrm{y}=0.3475 \mathrm{x}+1.2591$ & 0.733 & $/$ & $/$ & 3.52 & 2.88
\end{tabular}


Langmuir model gave the highest $R^{2}$ values which were greater than 0.96 . Conformation of the experimental data into the Langmuir isotherm equation proved that the surface of CNAC for MB adsorption was made up of homogeneous adsorption patches with monolayer coverage of $M B$ onto CNAC [9]. The monolayer saturation capacity of CNAC was found to $64.98 \mathrm{mg} / \mathrm{g}$ at $30^{\circ} \mathrm{C}$.

\section{Adsorption Kinetics}

All the experimental and calculated $\mathrm{q}_{\mathrm{e}}$ values obtained from the pseudo-first-order and pseudo-second-order kinetic model for adsorption of $\mathrm{MB}$ at $30^{\circ} \mathrm{C}$ are tabulated in Table 3 . Comparing the $R^{2}$ values, pseudo-second-order model showed a significant agreement with adsorption mechanisms, which indicated the chemisorption with the heterogeneous active sites occurred on the surface of CNAC [11].

Table 3: Parameter values of the kinetic studies of the adsorption of MB onto CNAC.

\begin{tabular}{ccccccc}
\hline & \multicolumn{3}{c}{ Pseudo-first-order } & \multicolumn{3}{c}{ Pseudo-second-order } \\
\cline { 2 - 7 } $\begin{array}{c}\mathrm{MB} \\
\text { concentration }\end{array}$ & $\begin{array}{c}\mathrm{q}_{\mathrm{e}^{\prime}} \mathrm{cal} \\
(\mathrm{mg} / \mathrm{g})\end{array}$ & $\mathrm{R}^{2}$ & $\mathrm{~K}_{1}$ & $\begin{array}{c}\mathrm{q}_{\mathrm{e}^{\prime}} \text { cal } \\
(\mathrm{mg} / \mathrm{g})\end{array}$ & $\mathrm{R}^{2}$ & $\mathrm{~K}_{2}$ \\
\hline $10 \mathrm{mg} / \mathrm{L}$ & 8.47 & 0.9721 & 0.3284 & 8.45 & 0.9278 & 0.1553 \\
$25 \mathrm{mg} / \mathrm{L}$ & 18.46 & 0.9447 & 0.6468 & 25.97 & 0.9946 & 0.069 \\
$50 \mathrm{mg} / \mathrm{L}$ & 29.59 & 0.9343 & 0.4191 & 36.63 & 0.9663 & 0.0626 \\
$80 \mathrm{mg} / \mathrm{L}$ & 42.60 & 0.8889 & 0.231 & 39.53 & 0.9876 & 0.0577 \\
$100 \mathrm{mg} / \mathrm{L}$ & 50.99 & 0.777 & 0.1965 & 45.25 & 0.9908 & 0.0575 \\
\hline
\end{tabular}

\section{Conclusion}

CNAC was found to be suitable for the removal of MB from aqueous solution. Adsorption of $M B$ was found to increase with increase in contact time and initial dye concentration. The Langmuir isotherm model was well described by the equilibrium data with maximum adsorption capacity of $64.98 \mathrm{mg} / \mathrm{g}$. The pseudo-second-order kinetic model fits well with the kinetic data.

\section{Acknowledgment}

The authors are grateful for the funding from Solid Waste Management Cluster, USM (1001/CKT/870023) and research grant from Ministry of Science, Technology and Innovation (MOSTI), Malaysia.

\section{References}

1. Afifah N, Saleh R. Removal of methylene blue dye contaminant by combination of ultrasonic and visible light irradiation using perovskite $\mathrm{LaMnO}_{3}$ nanocatalyst. Materials Science Forum. 2016; 864: 99-105.

2. Amin N. Removal of direct blue-106 dye from aqueous solution using new activated carbons developed from pomegranate peel: Adsorption equilibrium and kinetics. Haz Mater J. 2009; 165(1-3): 52-62. doi: 10.1016/j.jhazmat.2008.09.067

3. Ghaedi M, GolestaniNasab A, Khodadoust S, Rajabi M, Azizian S. Application of activated carbon as adsorbents for efficient removal of methylene blue: Kinetics and equilibrium study. Ind Eng Chem J. 2014; 20(4): 2317-2324. doi: 10.1016/j.jiec.2013.10.007

4. Kumar A, Jena HM. Removal of methylene blue and phenol onto prepared activated carbon from Fox nutshell by chemical activation in batch and fixed-bed column. Cle Prod J. 2016; 137: 1246-1259. doi: 10.1016/j.jclepro.2016.07.177

5. Langmuir I. The adsorption of gases on plane surfaces of glass, mica and platinum. Journal of the American Chemistry Society. 1918; 40(9): 1361 1403. doi: $10.1021 / j a 02242 a 004$

6. Freundlich HMF. Over the adsorption in solution. Journal of Physical Chemistry. 1906; 57: 385-470.

7. Langergren S, Svenska BK. Zurtheorie der sogenannten adsorption geloesterstoffe, Veternskapsakad. Handlingar. 1898; 24: 1-39.

8. Ho YS, McKay G. Sorption of dye from aqueous solution by peat. Chem Engg J. 1998; 70(2): 115-124. doi: 10.1016/S0923-0467(98)00076-1

9. Ahmad MA, Rahman NK. Equilibrium, kinetics and thermodynamic of Remazol Brilliant Orange 3R dye adsorption on coffee husk-based activated carbon. Chem Engg J. 2011; 170(1): 154-161. doi: 10.1016/j. cej.2011.03.045

10. Tan IAW, Ahmad AL, Hameed BH. Adsorption isotherms, kinetics, thermodynamics and desorption studies of 2,4,6-trichlorophenol on oil palm empty fruit bunch-based activated carbon. Haz Mater J. 2009; 164(2-3): 473-482. doi: 10.1016/j.jhazmat.2008.08.025

11. Ahmad F, Daud WMAW, Ahmad MA, Radzi R. Using cocoa (Theobroma cacao) shell-based activated carbon to remove 4-nitrophenol from aqueous solution: Kinetics and equilibrium studies. Chem Engg J. 2011; 178: 461-467. doi: 10.1016/j.cej.2011.10.044 